\title{
HANDLE WITH CARE: COACHING MULTI-DIVERSE PROJECT GROUPS TO BECOME HEALTHY DESIGN TEAMS
}

\author{
Bas FLIPSEN and Stefan PERSAUD \\ Delft University of Technology, Industrial Design Engineering, Delft, The Netherlands
}

\begin{abstract}
In the IPD master's in Industrial Design Engineering (TU Delft) we see a growing diversity in students. In recent years, the number of international students has grown to more than a third. Besides nationalities we also see differences in prior education, socio-emotional aspects and competences. In one of the master's courses Advanced Embodiment Design (AED), students work in teams on a client-based design project for one semester (21 European Credits). The student teams are supervised by coaches on a weekly basis. In recent years we increasingly noticed that the differences in background can lead to complications within the various teams. Examples are communication confusion, frustration and sometimes interpersonal collisions. There is a growing gap between the team members on cognitive and socio-emotional aspects and their ability to deal with this constructively. Within our team of coaches, we therefore focus mainly on keeping teams functioning in a healthy way and to a lesser extent on content and project results. With this course we want to offer students the opportunity to experience and perform in a successful team, acknowledge every student input and experience a successful result. To implement this vision and support our student teams, we started out with a project-group tracking-system using key performance indicators (KPI's). The KPI's gave the group of coach's insights in the performance of their own student groups relative to that of other groups. With this tracking system we could quickly pinpoint troublesome groups and individuals, which were used to lead our discussions during weekly coach meetings. During our weekly meeting we only discussed troublesome groups and tried to come to applicable solutions which could be implemented immediately. The solutions were found in literature, experiences within our own coach team, and making use of external experts. This paper presents our findings on improving multi-diverse team-performance by close tracking of their performance. We will focus on three major aspects of our findings: measuring student projects' performance during the course, our experience and dealings with diversity in student teams, and on how the collaborating coach-team helped in maximizing student-team performance.
\end{abstract}

Keywords: Team performance, multi-diverse student group, monitoring and coaching

\section{INTRODUCTION}

In the master's in Industrial Design Engineering (TU Delft) we see a growing diversity in students. In recent years, the number of international students has grown by more than a third. We also see differences in prior education, especially compared to our own bachelor's degree. In the master's course Advanced Embodiment Design, students work in teams on a client-based design project for one semester (21 European Credits). The student teams are supervised by teachers on a weekly basis. In addition to content, the coaches mainly coach on group dynamics. In recent years we increasingly noticed that the multicultural background, various preparatory schools and differences in knowledge levels can lead to complications within the various teams. Examples are communication confusion, frustration and sometimes interpersonal collisions. There is a growing gap between the team members on cognitive and socio-emotional aspects and their ability to deal with this constructively. We also noticed that for the team of coaches it became more difficult to coach these increasingly more diverse student groups because of a lack of knowledge in dealing with it.

The common goal of our team is to coach our student teams to the maximum of their performance, with our focus on stability and good flow within the team. To our believes the quality of the project results will follow from this. We therefore focus on keeping teams functioning in a healthy way and to a lesser 
extent on content and project results. We believe that healthy teams will result in maximum team performance and thus team results. With the course we want to offer students the opportunity to experience and perform in a successful team and recognize and acknowledge the multi-diversity within their team. We want to teach them to appreciate the different expertise's and skills of other master's students and let them perceive this as an opportunity for personal and group development.

In previous years the coach meetings consisted of discussions where all project teams were evaluated sequentially, which was tiresome and enduring. During these meetings there was no time to deal with all project groups individually which resulted in poor insight in the teams' performance and difficulties to deal with problematic team dynamics. It was mere serendipity when we found problems which needed our immediate attention. To improve our coaching and support our student teams we wanted to pinpoint the problems quickly and come to immediate solutions using literature-based interventions. In the course of 2018-2019 we started out with questions concerning: (i) the type of problems which might occur within multi-diverse student-teams, (ii) how to pinpoint and monitor these problems during the course, and (iii) how to immediately deal with them getting student-teams back on track as soon as possible.

\section{APPROACH}

To implement a quick and easy overview of the performance of our student teams we started out with a project-team tracking system, which kept track of the performance and the healthiness of the student team on a regular basis. We used Google forms to aggregate data in a weekly coach journal. Every week all our coaches entered their journal in the sheets which in turn was used as input for our weekly meeting. The performance is tracked by means of 6 key performance indicators (KPI's) [1], and a textual journal consisting of problems within the team, project progress and other stuff. Table 1 show the KPI's and the way we scored every one of them during the course. We differentiated between strategic KPI's, which monitors the progress of the student team in relation to the end goal, and operational KPI's, which monitors the team dynamics.

Table 1: The used strategic and operational KPI's used to monitor the teams' performance during the course

\begin{tabular}{|c|c|c|c|c|c|}
\hline Strategic KPI & 1. Low & 2 & 3. Moderate & 4 & 5. Good \\
\hline $\begin{array}{l}\text { Definition of key } \\
\text { challenges }\end{array}$ & Not available & $\begin{array}{l}\text { discussed but } \\
\text { not formulated }\end{array}$ & $\begin{array}{l}\text { discussed and } \\
\text { formulated, not } \\
\text { validated with } \\
\text { coach }\end{array}$ & $\begin{array}{l}\text { defined, } \\
\text { validated with } \\
\text { coach }\end{array}$ & $\begin{array}{l}\text { defined, } \\
\text { validated with } \\
\text { client }\end{array}$ \\
\hline $\begin{array}{l}\text { Definition of } \\
\text { research questions }\end{array}$ & Not available & $\begin{array}{l}\text { discussed but } \\
\text { not formulated }\end{array}$ & $\begin{array}{l}\text { discussed and } \\
\text { formulated, not } \\
\text { validated with } \\
\text { coach }\end{array}$ & $\begin{array}{l}\text { defined, } \\
\text { validated with } \\
\text { coach }\end{array}$ & $\begin{array}{l}\text { defined, } \\
\text { validated with } \\
\text { client }\end{array}$ \\
\hline $\begin{array}{l}\text { Definition of } \\
\text { method of } \\
\text { approach }\end{array}$ & Not available & $\begin{array}{l}\text { discussed but } \\
\text { not formulated }\end{array}$ & $\begin{array}{l}\text { discussed and } \\
\text { formulated, not } \\
\text { validated with } \\
\text { coach }\end{array}$ & $\begin{array}{l}\text { defined, } \\
\text { validated with } \\
\text { coach }\end{array}$ & $\begin{array}{l}\text { defined, } \\
\text { validated with } \\
\text { client }\end{array}$ \\
\hline Operational KPI & 1. Low & 2 & 3. Moderate & 4 & 5. Good \\
\hline $\begin{array}{l}\text { Project } \\
\text { management } \\
\text { approach }\end{array}$ & Not available & $\begin{array}{l}\text { Project } \\
\text { management } \\
\text { approach has } \\
\text { been chosen } \\
\text { but not } \\
\text { implemented }\end{array}$ & $\begin{array}{l}\text { Implemented } \\
\text { project } \\
\text { management } \\
\text { approach }\end{array}$ & $\begin{array}{l}\text { Project } \\
\text { management is } \\
\text { varying } \\
\text { successfully } \\
\text { implemented }\end{array}$ & $\begin{array}{l}\text { Successfully } \\
\text { implementatio } \\
\mathrm{n} \text { of project } \\
\text { management } \\
\text { approach }\end{array}$ \\
\hline $\begin{array}{l}\text { Planning (on-time } \\
\text { completion) }\end{array}$ & Not available & $\begin{array}{l}\text { Most items run } \\
\text { behind } \\
\text { schedule }\end{array}$ & $\begin{array}{l}\text { Most items are } \\
\text { on track, but } \\
\text { some behind }\end{array}$ & $\begin{array}{l}\text { All items are } \\
\text { on track }\end{array}$ & $\begin{array}{l}\text { More items are } \\
\text { addressed than } \\
\text { planned } \\
\text { (progressive } \\
\text { planning) }\end{array}$ \\
\hline Group Dynamics & $\begin{array}{l}\text { No flow in the } \\
\text { group }\end{array}$ & $\begin{array}{l}\text { Bad flow (two } \\
\text { opposed } \\
\text { groups or } \\
\text { issues with }\end{array}$ & $\begin{array}{l}\text { Some flow } \\
\text { (still some } \\
\text { issues with two } \\
\text { individuals) }\end{array}$ & $\begin{array}{l}\text { Moderate flow } \\
\text { (still some } \\
\text { issues with } \\
\text { only one } \\
\text { individual) }\end{array}$ & $\begin{array}{l}\text { Good flow in } \\
\text { the group (no } \\
\text { issues) }\end{array}$ \\
\hline
\end{tabular}




\begin{tabular}{|l|l|l|l|l|l|}
\hline & & $\begin{array}{l}\text { more than two } \\
\text { individuals) }\end{array}$ & & & \\
\hline $\begin{array}{l}\text { Perceived stress } \\
\text { levels }\end{array}$ & Catastrophic & Major & $\begin{array}{l}\text { Moderate } \\
\text { healthy }\end{array}$ & Minor & None \\
\hline
\end{tabular}

To present the data in a quick and handy format we produced a performance dashboard using Google Sheets (Figure 1). This gave us a quick insight in the performance of the different groups relative to each other, see top left bar chart. With the historical average (light blue) and the current team performance (dark blue) we can pinpoint the low and high performing teams and discuss them using the project-specific data, see top right. Besides the team name and coach this data consists of average historical performance per KPI, the latest update and the positive (green) or negative (red) changes in performance over time. In the example, for instance, it shows that team 3 has improved on all aspects but for the "methods of approach" where the performance dropped with 0.8 point. Besides the quantitative KPI's the dashboard also shows the coaches' journal about the team (down right). This journal is used to pinpoint the exact problems with this group and fire-up the discussion within the coach team and come to solutions on dealing with them.

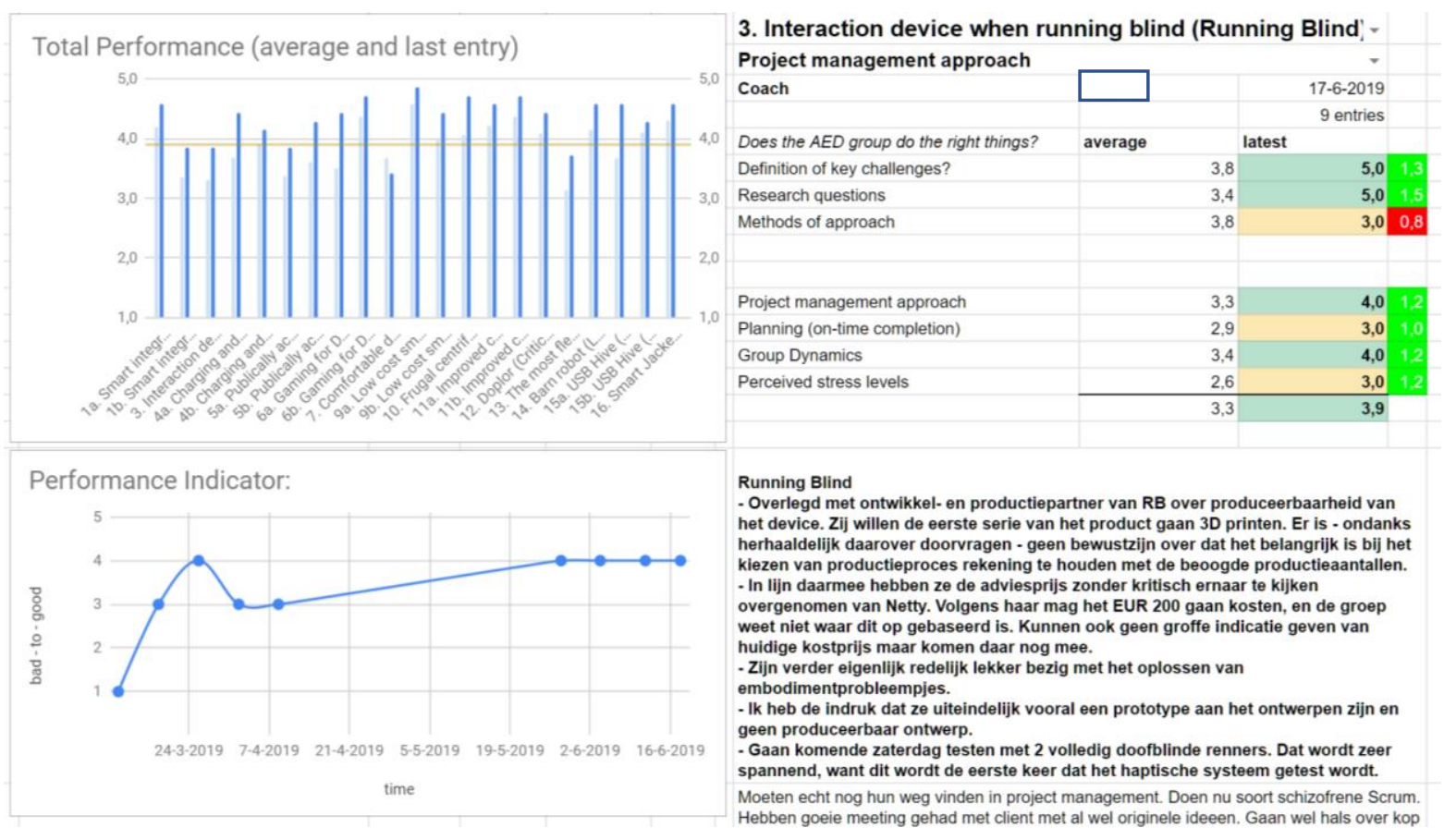

Figure 1. An example of the Performance Dashboard used to track student teams' performance

With this tracking system we could quickly pinpoint troublesome groups and individuals. The insights were used to lead our discussions during weekly coach meetings. Instead of discussing all student groups individually we could focus on problematic groups and come to solutions which could be implemented immediately. Solutions were found within the diverse knowledge fields found in our own team of coaches or were introduced by external experts. Issues concerning, amongst others, multi-cultural differences and socio-emotional aspects were in this way effectively tackled without loss of time.

The tracking system provided insight to classifying teams to the three categories of response within a team from Theory U [3]: muddling through (denial), moving apart (absencing) or moving together (presencing). Solutions derived from Theory U strategies by the expert, helped identify teams as being in denial or absencing, and move towards the presencing stages.

As part of the course we introduced an interactive lecture on reflection. Students were asked to do a group and personal reflection exercise based on the book Reflection Methods [4]. The teacher expert selected 3 exercises focusing on structuring and analysing: reflection with symbols, Kolb learning cycle, reflection on own performance with logical levels of Bateson. We used one additional reflection method 
to stimulate creativity: reflection with proverbs. All students handed in group and personal reflections according to the provided formats.

\section{RESULTS}

By keeping track of the 22 student-teams' performance and discuss them in the weekly coach meetings we pinpointed four typical problems occurring in the development of student groups becoming highly functioning teams.

\subsection{Cultural differences}

Group A consisted of a Dutch company coach, four Chinese students, a Spanish student and a Dutch project coach. The student group weekly confirmed they were working fine, while the coach and client expressed the group did not follow up on agreed actions and results. The coach and client did not seem to get through and connect with the student group. After consistent scoring low on the performance dashboard and sharing in the weekly discussions, we consulted an expert on multi culturality. She pinpointed the different perspective on communication and time of Asian cultures compared to the Dutch culture based on The Culture Map [2]. The client, coach and student group discussed these differences and that led to a better understanding, improved communication on expectancies and better functioning team with good project result.

\subsection{Design approach differences}

Group B consisted of a Dutch company coach, four Chinese students, a Spanish student and a Dutch project coach. During the weekly discussions the coach expressed the group was not following the agreed project approach. He discussed it with the students but the performance stayed low. One of the other coaches, a team dynamics expert, attended to the coach meeting. Through a dialogue concerning design approaches they revealed the Chinese students were trained in a different design approach and very hesitant to embrace the Delft Design approach. The dialogue sessions referring to Theory U phase of "Seeing" [3] created an understanding and more open minded group. Finally the group started combining their own approach with the Delft approach and delivered a satisfactory result.

\subsection{Emotional differences}

Group C consisted of Dutch students, Dutch company and Dutch coach. The group was formed on their own preferences and started very enthsiastically. The coach noticed the performance on team dynamics was dropping rapidly from high to low. During the coach meetings the coach shared his notes from the journals. It became clear there was a growing tension in the group. Being a group dynamics and communication expert, he facilitated a conversation where students shared their perspective on the tension. All team members were instructed to use a dialogic approach and listen without judgement, according to the first phase of The Five Dysfunctions of a Team [5,6]. It turned out there was a developing mistrust within the group, relationship stress and failed previous courses. The session ended with a decision made with consent where one member of the group choose to be relocated to another group. The group continued to built on regaining trust and finished the project with a satisfactory result. Most of all they experienced all 5 levels, stayed friends and developed into designers equipped with knowledge and skills on teamdynamics for future projects.

\subsection{Competencies differences}

Group D consisted of a Dutch company coach, four Chinese students, one Indian student, one Dutch student and a Dutch project coach. After dividing tasks within the group and seeing the results, the coach noted in her journal the group was meeting the planning but the quality of the results was poor with some students. During the coach meeting she shared her concerns and the coach group discussed options for interventions. The coach addressed the poor quality during project meetings but that did not improve the results. Finally another coach attended the project meeting to support a guided dialogue conversation on the topic. It became clear some students were very uncomfortable sharing their lack of competence in certain design engineering areas. They were assigned for the task, did their best to meet the quality but were never trained in that expertise during their bachelor studies. We combined an approach of building trust to repair the dysfunctioning of the team [5,6], knowing each others background when entering the $U$ field [3] and improving insight of cultural patterns of behaviour and belief [2]. The group 
found a system of team buddies where a competent and non competent team member joined in activities. This resulted in a good functioning team and they passed the project succesfully.

\section{CONCLUSIONS}

The performance dashboard is very helpful as a 'reflection-in-action' tool for coaches. It clarifies which teams have troubles, what the nature of the problem is, and it shows the tendency, all in one view. It takes the coaches only a few minutes to fill in the form but raises the awareness during the coaching session with students. Therefore, incidents can be addressed in real time. The coach meetings also gain relevance and become a place to share concerns. Therefore, these meetings have an increased feeling of security and the team of coaches also becomes a better team. What could be improved are the selection and descriptions of KPI's. We used the same KPI's throughout the whole project, but they might increase in relevance if they would change along the development of the course.

Reflection at the end of the project is helpful but for some students it feels like it is something done at the last moment and it interferes with other project deadlines. Therefore, it decreases in its learning effect. Preparing students better by also providing a lecture halfway the project and experimenting with several reflection methods during the project could improve the quality and effect of the reflections. Putting the deadline of the final reflection before the project presentation deadline might also improve the effort students put into it. The Culture Map by Meyers proved to be a good framework for addressing cultural differences. It helped the student groups to become aware of differences. It proved to be helpful in solving issues of cultural differences, especially on communication and planning. We are curious if providing it to both coaches and students beforehand will help in preventing negative framing. Thus, shifting cultural diversity in teams from a negative aspect to a positive aspect where you can broaden your scope and see it as an opportunity for growth. Theory $U$ seems to be an overall good model which combines all addressed issues of multi-diverse project groups with the stages of a design project. It provides three directions teams are going: downloading (muddling through), presencing (moving together) or absencing (moving apart). Especially the first phase of becoming aware of the downloading patterns proved to be a key factor. It incorporates the biases students and coaches can have culturally, competencies, emotionally and design strategies. Facilitating "seeing" each other with fresh eyes, using the Culture Map, sharing biographies using dysfunctions of a team, practising dialogue and reflecting together, lays the foundation for future cooperation dealing with multi diversity.

Based on the problems during the course we implemented several interventions. These interventions always started with a dialogue between the coach, an expert and the student team. We implemented four interventions successfully. The first intervention was a dialogue to create awareness of cultural differences by showing the differences to each other without judgement and clarifying each other's needs. This helped in building trust within the team and made the team perform at a higher level. The second intervention was to develop a sensitivity for each other's wellbeing and combine strengths and see weakness as a developmental opportunity. Buddying-up with a teammate is an intervention where students learn from each other, improve their skills and on-the-side understand each other better. The third intervention concerned a team with emotional issues. Within this group we had a dialogue where we implemented the "Open Mind, Open Heart and Open Will" approach from Theory U. This resulted in a consent descision within the team. They did not all agree on an individual level but on a team level we found a solution everybody could agree on. The fourth intervention involved a team with different design approaches. A dialogue session referring to Theory U phase of "seeing" created an understanding and more open minded group. The group started combining their own individual approaches and came to a satisfactory result.

During the course Theory $\mathrm{U}$ supported the team of coaches on different levels using different dialogue techniques. At this moment this model is not well known within product-design education because it is multi-level approach focussing on personal development within the group context and not only on teamdynamics. To create greater impact we think, developing a teaching course for all coaches to be skilled more on Theory $\mathrm{U}$ is very important for the new course.

\section{REFERENCES}

[1] Marr, B., Key Performance Indicators (KPI), Pearson Education Limited, 2012

[2] Meyer, E. The Culture Map, Public Affairs, New York, 2014

[3] Scharmer, O. Theory U, Leading from the Future as it Emerges, Berett-Koehler Publishers, 2016 
[4] Gordijn, F. et al, Reflection Methods, Wageningen Centre for Development Innovation, Wageningen University \& Research, 2018

[5] Lencioni, P. The Five Dysfunctions of a Team, Jossey-Bass, 2002

[6] Lencioni, P. Overcoming The Five Dysfunctions of a Team, Jossey-Bass, 2005 